\title{
Improving the Attitude of Pre-service Elementary School Teachers Towards Teaching Physics
}

\author{
Nina Abramzon 1, *, Stefanie Saccoman ${ }^{2}$, Barbara Hoeling ${ }^{3}$ \\ ${ }^{1}$ Department of Physics and Astronomy Pomona, California State Polytechnic University, CA, USA \\ ${ }^{2}$ Pomona Unified School District, Pomona, CA, USA \\ ${ }^{3}$ Hochschule Landshut, University of Applied Sciences, Landshut, Germany
}

Email address:

nabramzon@cpp.edu (N. Abramzon)

${ }^{*}$ Corresponding author

\section{To cite this article:}

Nina Abramzon, Stefanie Saccoman, Barbara Hoeling. Improving the Attitude of Pre-service Elementary School Teachers Towards Teaching Physics. International Journal of Elementary Education. Vol. 6, No. 3, 2017, pp. 16-23. doi: 10.11648/j.ijeedu.20170603.11

Received: June 9, 2017; Accepted: June 21, 2017; Published: August 1, 2017

\begin{abstract}
The dislike that many elementary school teachers have for teaching physics is a well-known problem that adversely affects science education at all higher levels. This study aims at evaluating an approach to change this negative attitude by demonstrating the relevance of science teaching to the students in the SCI 210 course, "Physics for future elementary school teachers". Several new elements were introduced in this integrated activity-based course: a historical perspective on the state of science education in the U.S.A., a collaboration with a faculty member from the college of education as well as with educators from the NASA/JPL Office of Education, and a physics teaching experience with middle school children. To gage the effectiveness of this approach, attitudinal surveys were implemented at the beginning and again towards the end of the course. The data show that the attitude towards science teaching of the students improved significantly due to their experience in the "reformed" course. In contrast, in the unreformed course which lacked the above enrichment elements, there was little or no change in the students' attitudes between the pre- and post-survey.
\end{abstract}

Keywords: Attitude, Science, Physics, Preservice Teacher Education

\section{Introduction}

The low numbers of students in the U.S. that major in science and engineering in general, and in physics in particular, is an issue of great concern and a problem that will adversely affect the American economy and security in the future. In the search for the causes why students avoid STEM (Science Technology Engineering Mathematics) majors, high school curricula are often blamed for destroying their interest in science and especially in physics. While students' disinterest in science often does not become evident until junior high or high school when they have to choose what courses to take, most kids who decide not to pursue scientific or technical subjects have already made up their mind while still in elementary school $[1,2,3]$ when they have only received instruction from K-6 teachers.

These teachers, who are expected to instruct their young students in multiple subjects ranging from reading and writing to mathematics and arts, generally do not consider themselves to be scientists. The education and training they receive in preparation for their careers is typically much different from that of scientists and engineers and often inadequate in the area of science, leaving many of them severely underprepared for this subject. Surveys of elementary (K-6) school teachers conducted at both state and national levels found that U.S. teachers indeed often feel under-qualified to teach science $[4,5,6,7,8]$, with only $22 \%$ nationwide reporting that they felt qualified, versus $63 \%$ that consider themselves qualified to teach reading. In addition, K-6 teachers often regard what little exposure they may have had to science as a negative experience, and they harbor some reluctance to teaching or increasing their own knowledge of science. Not surprisingly, these negative attitudes and feelings towards science as well as the elementary school teachers' comprehension of the subject influence how effectively they teach it $[9,10]$. In other 
studies, it was found that "attitudes and beliefs play significant roles in shaping teachers' instructional practices." [11] Of even greater concerns are the findings that these negative attitudes of teachers toward science and scientists are often passed on to their students [12], and with a high probability are ultimately one of the causes for the shortage in STEM students.

While many efforts have been made in recent years to improve the pre-service elementary school teacher education, their focus has been for the most part to increase the teachers' content knowledge in the sciences [13] and about the nature of scientific knowledge, about science as a human endeavor, and the unifying concepts and processes of science [14, 15]

However, the attitudes of future teachers towards science and science teaching have to be considered as well. Some attitude studies on a mix of non-science students and preservice teachers have been done [16], showing that preservice elementary teachers who have a favorable attitude towards science are more likely to actually teach it - rather than avoid it - once they begin teaching professionally. Research has also shown that elementary teachers who have a positive attitude toward science teach it with a higher level of commitment and intensity than teachers with poorer attitudes [17]. Clearly, teachers who maintain positive attitudes will likely be able to generate excitement over understanding how the world works, stimulate children's creativity, and make the learning experience more enjoyable. However, teachers who are uneasy with science subject matter are less likely to spend the time and effort required to teach it well, whether their discomfort may arise from their own bad experiences in science classes or from feelings that they have insufficient education or training in the sciences.

Various studies [18, 19] have indeed shown generally low levels of scientific and technological literacy among preservice and in-service primary school teachers that correlate with negative attitudes toward science. These attitudes often originate from negative experiences that teachers had during their own primary and secondary education, and persist during their preservice teacher training [3, 17, 20, 21, 22]. Studies investigating the attitudes of primary teachers toward science have indicated that teachers with less positive attitudes share a number of characteristics. They have lower confidence and poorer opinions about their abilities to teach science $[22,23]$, they spend less time discussing and teaching these topics in their classrooms $[19,24]$, they rely more on standardized methods and top-down instruction [19, 25, 26], and they are less able to stimulate the attitudes of their students $[19,26]$. It is evident from this research that training teachers to cover science topics effectively in the classroom is not only a matter of filling gaps in their knowledge of the subject matter, but also of helping them to overcome negative feelings or beliefs they may have about science [27].

In the redesign of the SCI 210 course "Physics concepts and activities" for future elementary school teachers at California State Polytechnic University, Pomona (CPP), a strong emphasis was put on improving the students' attitude towards physics. By implementing a student teaching experience in an elementary/middle school classroom, and by involving experienced educators as guest lecturers, the relevance of the course and its connection to real-life teaching to the students was demonstrated. In this paper, the elements of this redesigned course are described, and the results of student attitude surveys administered at the beginning and the end of the course are reported, and finally conclusions on the effectiveness of this approach are presented.

\section{Background}

In the physics department at CPP, SCI 210 is a mandatory course for future elementary school teachers aimed at enhancing their knowledge of and enthusiasm for science. The course is widely unpopular with students, often triggering negative feelings among those enrolled ranging from anxiety to outright hostility. Others have reported similar apprehension toward physics among pre-service teachers [28].

These attitudes are certainly consistent with the negative opinion of the general public towards physics in particular. Given the fact that only $1 \%$ of the nation's high school students even enroll in a physics course, one can assume that most future elementary school teachers have not been exposed to the subject matter in years. It should therefore come as no surprise that many pre-service teachers are less than enthusiastic about taking SCI 210. Meeting like-minded individuals in class merely validates the individual feelings or perceptions, and the "physics haters" quickly become a powerful group that creates a self-perpetuating classroom culture of resistance and boredom.

Another major reason the course is so poorly received is that many students feel the material is largely irrelevant to their careers and does not sufficiently address the pedagogical aspects of teaching elementary school children. This problem is exacerbated by the fact that the course is typically taught by physics professors from the College of Science who are familiar with the various approaches to teaching science to university science and engineering students, but are less attuned to the broader instructional techniques that are central to the College of Education curricula.

This work aims to answer the question of whether the attitudes among SCI 210 students (all pre-service teachers) toward the course and the subject matter can be improved by introducing elements that demonstrate how the course is relevant to their intended careers.

\section{Method}

The project team (lead and co-authors) looked toward widely accepted national educational reform documents as a source of information for changing the conditions of the learning environment. One such document was "Remarks at President's Conference on Teacher Quality" [29] that stated, "Our college and university teacher education systems 
have... frequently fallen short. Our colleges of education... must have the support of the entire university, and enjoy much stronger links with the colleges of arts and science. Education students must achieve competence in the subject matter they will teach." Thus, SCI 210 instructors reached out to College of education faculty. The course was structured with feedback from a College of Education professor, who also presented her views and experience of science teaching in guest lectures. In addition, the field experience component for the SCI 210 students was implemented in close collaboration between the Colleges of Science and Education.

The textbook used in the SCI 210 course is "Inquiry into Physical Science - a contextual approach" by Roger Nanes (Volume 1: Global Warming) [30]. The data taken and analyzed by Loverude et al. [31] suggest that using the methods and activities approach improves student understanding of selected topics, often dramatically.

Enrollment in each class is capped at 24, and all class activities take place in a dedicated lab classroom. There are six fixed tables in the room; each seats four or five students. Most classroom time will involve students working together in small groups. The course seeks to model the way science should be taught in the elementary school: with small-group hands-on activities and discussions, as well as experimental measurements and pencil-and-paper activities. In a variety of activities, student groups prepare white boards to present their analysis of a situation or experiment to the entire class. Course activities emphasize conceptual understanding and science process skills, i.e., having students learn how to ask questions, make predictions, gather evidence, and make inferences. While the materials are effective in explaining content and are consistent with current accepted pedagogical methods, they are lacking elements that show the students the relevance of the course to their planned careers.

The following new elements to demonstrate this relevance were introduced:

(1). A section presenting the historical perspective on the nation-wide science education improvement efforts and more of the teaching techniques and pedagogical elements that the students are exposed to in their College of Education coursework, juxtaposed with the science concepts and science education disciplines of the College of Science.

(2). A faculty member from the College of Education volunteered as a guest lecturer in the SCI 210 class (which is ordinarily taught solely by faculty from the College of Science), to address the issue of why it is important for elementary school teachers to have a basic understanding of physics.

(3). NASA/JPL educational teacher support (grade level appropriate) materials are used, and a NASA/ JPL science educator guest presented in the class $(2.5$ hour lesson including, "Make a thermometer and Calibrate It", "Make a Comet and Eat It," "Suited for Space Walking", and Laws of Thermodynamics, "There is No Free Lunch" \& "Entropy Always Wins"). A visit to the NASA/JPL Education Resource Center was also incorporated.

(4). A field teaching experience for the students was implemented, for students to practice and recognize the relevance of the course. They visited a local middle school and gave physics presentations to 6th grade students.

The course that included the four elements described above is referred to as the reformed course, and to the one without as the unreformed course. The reformed and the unreformed courses used the same textbook and the same learning by inquiry approach. The only difference between the two courses were the four elements described above that were introduced into the reformed course. These four elements resulted in somewhat less time for the content materials. As a result, the unreformed course had 1.5 more class meetings (out of a total of 20) devoted to content. The differences between the two course types in terms of topics covered or depth of coverage were therefore small. However, there is no question that the reformed course students put significantly more time into their SCI 210 class. Selecting a teaching activity, preparing for it and presenting it twice in school was certainly a challenging commitment of time and energy. But since these activities took place mostly outside of the regular class time, it essentially did not interfere with the coverage of the course content.

To help us gauge the effectiveness of this approach, an attitudinal survey was used. The survey was administered to the students of both the reformed and the unreformed course both at the beginning (pre-survey) and at the end of the course (post-survey).

\section{Results and Discussion}

\subsection{The Field Teaching Experience}

As part of the SCI 210 course, students were required to present a physics lesson to 6th graders in a local middle school. The choice of the school was due to the fact that one of the authors (S.S.) was the director of this school and therefore was in a position to make this teaching experience possible for our SCI 210 students. The legal, organizational, and logistical issues of having university students act as teachers in the classroom of a public school - even in the presence of a licensed teacher - must not be underestimated. For example, finger printing is required, and the university rules for insurance coverage (as in the case of field trips) must be followed. As our SCI 210 students aspire to become elementary school teachers for kindergarten to $5^{\text {th }}$ or $6^{\text {th }}$ grade (depending on the school district structure), the science teaching experience with $6^{\text {th }}$ graders would be greatly beneficial. The pre-service teachers worked in pairs to design a hands-on physics lesson that met a content of the California Science Teaching Standards, which had to be identified explicitly. The lesson had to include some of the following elements: anticipatory set to raise the level of interest for the lesson, instruction, guided practice, independent practice, 
assessment, and closure. The activities, each 30-45 minutes long, were centered around a physics experiment and designed as an inquiry-based experience for the children, in the same spirit as the lessons of the SCI 210 course itself. The future elementary school teachers were evaluated and graded on their presentation according to a given rubric by an experienced science teacher. This feedback allowed them to implement improvements when they presented the same lesson a second time to a different group of middle school students. The second presentation was evaluated as well, and both scores counted as part of their final course grade. The students were required to keep a journal describing their school visits. These journals included a description of what activities were done in the class (content, delivery, and how they related to the class curriculum, and to the California Science Standards), as well as their general assessment of how the activities were received by the students, what the students' interest level was, and what the pre-service teachers themselves and the school students learned or otherwise gained from the experience.

In addition to these journals, evidence on the effects of the teaching experience was gained by allowing time for discussion and reflection in nearly every SCI 210 class meeting. The instructor asked who had been presenting their activity during the past week, and encouraged a brief report of their experience. Due to the small class size of 24, the students quickly got to know each other and felt comfortable sharing their concerns and feelings about the teaching activity. When the SCI 210 students were initially told about these presentation requirements, they voiced apprehension that the children would not be interested in physics and therefore be bored. This apprehension could indicate that the teacher students either perceived physics as boring, perceived themselves as boring presenters, or a combination of the two. Further inquiry into the students' self-perception would be worth pursuing. Ultimately, two emotional reactions were observed in the university students concerning their presentations to the children. The first was considerable nervousness. The presenters either admitted their nervousness just prior to a presentation, and/or exhibited nervous behavior including high-pitched tones of voice, rapid speech, missed or incorrect word/s during an explanation, mild stuttering, or looks of frustration when something did not go just right the first time. The second emotion was that of complete surprise at the level of student engagement and excitement displayed by the children. The university students, upon completing the first presentation, mentioned their amazement that the children who participated, actually "got it", were volunteering to be helpers, thanked them with applause, called the presenters by name, and asked if they would come back. The reward of being accepted and appreciated by children most likely played an important role in the outcome of the SCI 210 students having a positive reaction to the course and seeing its purpose. When the presenters returned to present their lesson for the second time to a different group of middle-schoolers, they expressed that they were not nervous and actually looked forward to the second presentation.

These observations are consistent with a 1986 study by Strawitz and Malone [32] that demonstrated the effectiveness of field experience in preservice classes. Student teachers, some of whom were enrolled in classes with field experience requirements and some who were in classes without such a requirement, were given the Teachers' Concerns Questionnaire and the Science Teaching Attitude Scales before beginning their methods classes. The responses to these pretest surveys among the group with the field experience requirement were very similar to the responses of those without the requirement. After completing their methods classes, both groups showed little change in their concerns about teaching science, however the group with the field experience requirement showed significantly better attitudes toward science and science teaching.

\subsection{The NASA/JPL Education Resource Center Visit}

The Education Office at NASA's Jet Propulsion Laboratory works with NASA, mission teams, scientists, engineers, and educational organizations to provide students and educators with science, technology, engineering, and mathematics (STEM). It acquainted students with the array of teaching materials, designed educational activities, visual aids, etc. that NASA/JPL makes available to educators. Following the field trip, the students were asked to write a one page report reflecting on the experience. Many of the students indicated in their reports that before the trip, they thought it was going to be a waste of time, and did not realize until afterwards how beneficial this experience was for them. A majority of the students indicated that they definitely plan to use this resource once they become teachers and also recommend it to their friends who are not aware of this resource, an assertion which reveals that it is their intention to teach science. Some students indicated that following the trip they were much more enthusiastic about teaching science and are looking forward to using these resources once they teach science.

Additional examples of statements made by the students in these reports include:

a. "I believe the field trip was very beneficial because it offered me information on future aspects of being a teacher and that is something I haven't yet experienced in any of my classes. It really gave me a first glance on becoming a teacher."

b. "The trip to the NASA/JPL resource center was a great experience. I learned that there is a lot of information made available for teachers, students, or anyone interested."

c. "To be honest, I personally did not want to do the field trip and had anticipated something totally different then what I have experienced. I have been to JPL before and I thought that the resource center was going to be just about a bunch of information on space or the space program. I was surprised to see that this field trip was a great experience. I learned that resources are made available to the public and that there are resources for teacher." 
d. "Not many other classes I have taken have given me such an opportunity. It is nice to know that as a teacher I will not have to provide all the materials I need for the classroom."

e. "Now I am excited to learn more about this center and find out about other ones to help improve my teaching experience."

\subsection{The Attitude Survey}

The research method employed an 11-item attitude survey that was administered twice to the students: first at the beginning of the course before the start of instruction, and a second time at the end of the course.

Table 1. List of questions posed in the attitude survey.

\begin{tabular}{ll}
\hline Question \# & Survey Question \\
\hline 1 & A fundamental physics course is appropriate for someone becoming an elementary teacher. \\
2 & I am looking forward to teaching science content to students when I become a teacher. \\
3 & I can readily give examples of physics principles in everyday life. \\
4 & I like courses that allow me to discover things for myself. \\
5 & Elementary school students are interested in science. \\
6 & I study physics to learn knowledge that will be useful in my life outside of school. \\
7 & Nearly everyone is capable of understanding physics if they work at it. \\
8 & To understand physics I discuss it with friends and other students. \\
9 & The subject of physics has little relation to what I experience in the real world. \\
10 & Reasoning skills used to understand physics can be helpful to me in my everyday life. \\
11 & Understanding physics basically means being able to recall something you've read or been shown. \\
\hline
\end{tabular}

Table 1 shows a list of the survey questions. Questions 611 were adopted from the CLASS survey [33], an attitude survey developed at the University of Colorado in Boulder for science and engineering majors. We decided against using the CLASS survey in its entirety since it targets a very different audience. The questions omitted were those that were meaningless for our future elementary school teachers, e.g. those pertaining to quantitative problem solving and advanced mathematical methods. Instead, CLASS questions that were chosen are not specifically meant for STEM majors and address more general issues such as the usefulness of physics and its relation to everyday life, and the opinion the students might have on the way you study and learn physics: by discussion and reasoning with others, or by recalling memorized facts. Questions 1-5 were designed to address the specific research topics. Specifically, whether the students considered the SCI 210 course relevant for their career, what their feelings were towards teaching science in general and the method of inquiry in particular, and how they gauge the interest level in science in children was assessed. The survey had the format of a typical five-level Likert scale: strongly disagree (1), disagree (2), neutral (3), agree (4), strongly agree (5). The survey participants included six classes who had taken the reformed SCI 210 course $(n=138)$, and two classes who had taken the unreformed course $(n=45)$. We performed a statistical analysis of the survey data, using the unpaired Student-t-test. A t-value of 2.0 corresponds to a confidence level of $95 \%$ that there is truly a difference between the two groups that are being compared. Instead of indicating the confidence level, we report, as it is customary done, the p-value, which is computed as $(100-$ confidence level)/100. Differences were considered as significant if they have a t-value of 2.00 or higher, i.e. a p-value of 0.05 or lower (a confidence level of $95 \%$ or higher). In other words, a p-value of 0.05 for a particular question means a probability of $5 \%$ that there is no difference between the two groups. As one might expect, the results of the pre-surveys at the beginning of the course are essentially the same for the reformed and unreformed type ( $\mathrm{p}>0.4$ for all questions). Also, for questions 4, 9, and 10, there is neither a significant change from the pre- to post results for either class, nor a significant difference between the post-answers of the reformed and unreformed course participants. In the remainder of the analysis, the first focus was on the differences in the post-results of the reformed and unreformed classes.

Table 2. Average, standard deviation and p-value for the four questions with the largest differences between the reformed and unreformed post values.

\begin{tabular}{llllllll}
\hline \multirow{2}{*}{ Question } & reformed & & & unreformed & & post ref./ \\
\cline { 2 - 7 } & Pre & post & p-value & Pre & post & p-value & unref. p-value \\
\hline 1 & $3.64 \pm 0.87$ & $4.27 \pm 0.63$ & $<0.001$ & $3.53 \pm 0.87$ & $3.32 \pm 0.91$ & 0.25 & 0.001 \\
3 & $2.50 \pm 1.07$ & $3.81 \pm 1.07$ & $<0.001$ & $2.64 \pm 1.14$ & $3.32 \pm 1.41$ & 0.015 & 0.015 \\
5 & $4.00 \pm 0.71$ & $4.27 \pm 0.63$ & 0.002 & $4.08 \pm 0.68$ & $3.99 \pm 0.81$ & $>0.5$ & 0.02 \\
2 & $3.61 \pm 0.80$ & $3.75 \pm 1.30$ & 0.30 & $3.55 \pm 0.80$ & $3.45 \pm 1.08$ & $>0.5$ & 0.20 \\
\hline
\end{tabular}

Table 2 shows a list with the average score and standard deviation for those four questions that show the largest differences between the reformed and unreformed post values. The most notable difference is found for question 1
("A fundamental physics course is appropriate for someone becoming an elementary teacher."). With roughly $45 \%$ neutral and $45 \%$ agreeing in the pre-answers, the postanswers of the two courses are significantly different. In the 
unreformed course, the students' answers did not change much due to the course experience. After having gone through the reformed course, however, more than $80 \%$ of the students feel that this was a significant and appropriate experience for them. The conclusion is that the reformed course students now recognize the significance and relevance of our physics course for their work and careers as elementary school teachers. In the same way, the reformed course students feel that they can give readily examples of physics principles in everyday life (question 3). This shows that they have formed a connection with physics that is significantly stronger than that of their unreformed course peers. We believe that by developing science activities for the children, these student teachers were not only exposed to more areas of physics, but also had to make sense for themselves of the application of physics in the experiments they presented. At the end of the reformed course, students also feel that elementary school children are interested in science (question 5), significantly more so than at the beginning of the course, and significantly more so than their unreformed course counterparts. Clearly, having gone through the experience of teaching physics to children and observing their reaction has made a big impression on the students. A smaller difference between the post results of the two groups can be seen for question 2: The reformed course students are looking forward to teaching science somewhat more that the unreformed course students.
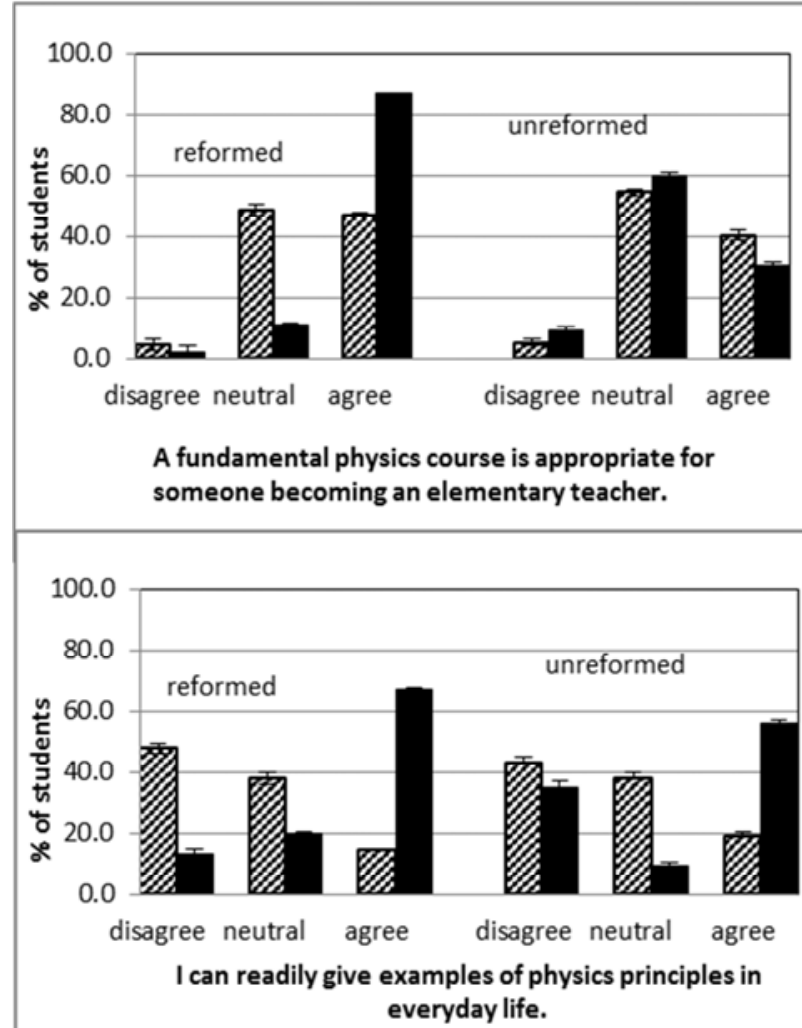

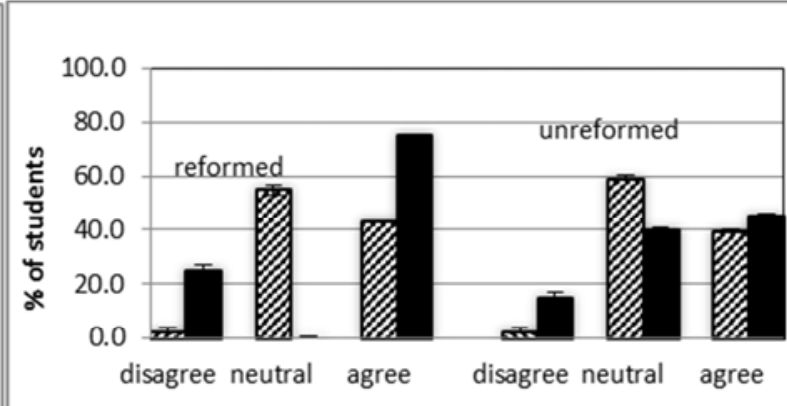

Elementary students are interested in science.

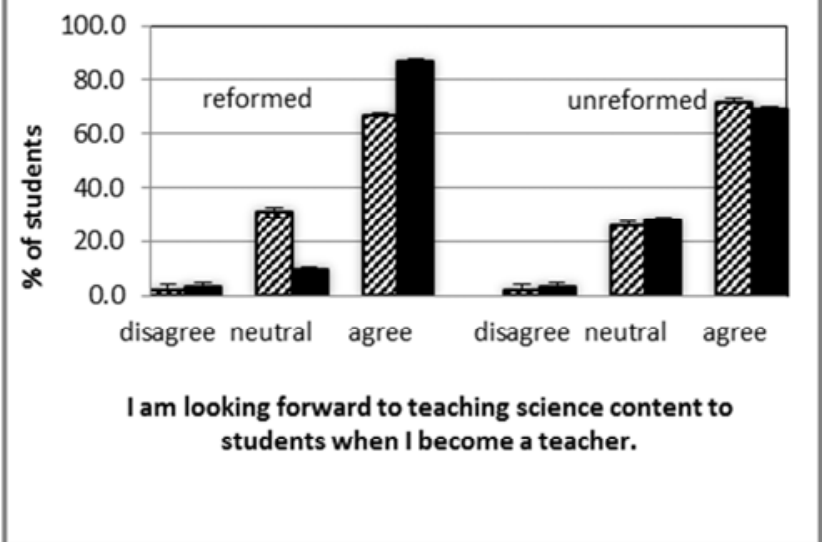

Figure 1. Survey results for select questions for the reformed course ( $n=138$, left side of the graphs) and for the unreformed course ( $n=45$, right side of the graphs), side by side. The pre-course results are in grey, the post results in black.

Figure 1 shows bar graphs of the survey results for the four questions discussed above, which show the greatest differences between the answers of the reformed and unreformed courses. The "strongly disagree" and "disagree" responses (as well as the "agree" and "strongly agree" responses) are combined for the purpose of clarity of the data presentation.

When comparing the pre- and post-answers of the same group, the reformed class a significant improvement in seven of the 11 questions, namely for questions 11, 8, 7, and 6 (in addition to questions 1,3 , and 5 , which was already discussed above). In contrast, for the unreformed class, the improvement between pre- and post-test was significant only for questions 3 and 11. A significant positive change in both the reformed and unreformed course can be observed in the answers to question 11 ("Understanding physics basically means being able to recall something you've read or been shown.”). Disagreement jumps from $20 \%$ to over $50 \%$, while agreement drops from $45 \%$ to $25 \%$. This change was attributed to the inquiry-based nature of the SCI 210 course, which is different from the memorizing of facts they might have encountered in their physics class in middle or high school. ( $\mathrm{p}<0.001$ for pre- to post change in the reformed course, and $\mathrm{p}<0.002$ in the unreformed.). Questions 6, 7, and 8, which were taken from the CLASS survey, show a significant improvement between the pre- and post- answers 
for the reformed class only. For question 6 ("I study physics to learn knowledge that will be useful in my life outside of school"), agreement increased from $40 \%$ to over $60 \%$ while the percentage of disagreeing students remained constant at about $10 \%(\mathrm{p}<0.01)$. For question 7 , ("Nearly everyone is capable of understanding physics if they work at it"), the increase in agreement was from $58 \%$ to $78 \%(\mathrm{p}<0.02)$. For question 8 ("To understand physics, I discuss it with friends and other students"), the shift from disagree to agree is significant as well, with a p-value $<0.001$. Therefore it is noted that the reformed course students are clearly demonstrating a change towards a more "expert-like" opinion of physics, which is tested by the CLASS questions. In the unreformed course students, on the other hand, their "expertstatus" in physics is much less improved, with only question 11 showing a significant change.

\section{Conclusions}

The efforts to demonstrate to SCI 210 students the relevance of the course to their planned careers included: class discussions of recent history in educational policy, obtaining the support of the NASA/Jet Propulsion Laboratory Office of Education, and providing the students with a formalized physics teaching experience of their own with children (coupled with a formal evaluation of their physics teaching). Following these efforts, an attitudinal shift in the positive direction was observed. Being accepted and appreciated by children most likely played a crucial role in the positive reaction to the course. The SCI 210 students felt that their considerable investment of time and energy into these science teaching activities had been acknowledged and rewarded beyond their initial expectations. This positive experience is encouraging for their future behavior as teachers. It is the hope is that they will continue to actually teach physics to their young students, thereby changing the kids' opinion and ultimately the public opinion for the better.

Clearly, future elementary school teachers cannot be turned into scientists, nor can their previous school experience with science be undone simply by taking a ten week long Physics Concepts and Activities course. However, a significant improvement in their attitude towards physics has been achieved by the implementation of the new course elements. Further research in similar science courses should be carried out to investigate their effectiveness beyond the specific SCI 210 course. In addition, longitudinal studies on the sustainability of the improved attitude and science teaching behavior are needed. As the importance of paying attention to the SCI 210 students' attitudes has been demonstrated, this aspect should be incorporated in any further science teaching training the future teachers may receive. In the same way, when in-service elementary school teachers are given the opportunity to brush up on their science teaching skills in professional development courses, instructors should pay careful attention to their attitudes as well, and deliver a boost to their excitement for physics along with the content matter.

\section{References}

[1] Osborne, J., \& Dillon, J. (2008). Science education in Europe: Critical reflections (Vol. 13). London: The Nuffield Foundation.

[2] Tai, R. H., Liu, C. Q., Maltese, A. V., \& Fan, X. (2006). Planning early for careers in science. Life sci, 1, 0-2.

[3] Young, B. J., \& Kellogg, T. (1993). Science attitudes and preparation of preservice elementary teachers. Science Education, 77 (3), 279-291.

[4] Gerlovich, J. A. (1981). How Essential is Science at the Elementary Level?. Science and Children, 19 (3), 22-24.

[5] Mechling, K. R. (1982). Preparing and Certifying Science Teachers: An NSTA Report. Science and Children, 20 (2), 9-14.

[6] Kunter, M., Frenzel, A., Nagy, G., Baumert, J., \& Pekrun, R. (2011). Teacher enthusiasm: Dimensionality and context specificity. Contemporary Educational Psychology, 36 (4), p 289-301.

[7] Brigido, M., Bermejo, M. L. \& Mellado, V. (2012). Selfefficacy and emotions in prospective primary education science teachers. In Bruguière, C., Tiberghien, A. \& Clément, P. (Eds.), E-Book Proceedings of the ESERA 2011 Conference: Science learning and Citizenship Part 12, 19-24. Lyon, France: European Science Education Research Association.

[8] Brown, T., Brown, K., Barnot, V., \& Nelson, D. (2014). Preservice elementary teachers' attitudes towards components of physical science: Do they differ from other post-secondary students?. Electronic Journal of Science Education, 18 (4).

[9] Morrisey, J. T. (1981). An analysis of studies on changing the attitude of elementary student teachers toward science and science teaching. Science education, 65 (2), 157-177.

[10] Ngman-Wara, E. I., \& Edem, D. I. (2016). Pre-Service Basic Science Teachers Self-Efficacy Beliefs and Attitudes towards Science Teaching. International Journal for Innovation Education and Research, 4 (8), 20-41.

[11] Jones M. G., Carter. G (2007). Science teacher attitudes and beliefs", In: Abel S (ed) Handbook of research on science teaching. Lawrence Erlbaum, Mahway.

[12] Czerniak, C., \& Chiarelott, L. (1990). Teacher education for effective science instruction-A social cognitive perspective. Journal of Teacher Education, 41 (1), 49-58.

[13] Goldberg, F., Price, E., Robinson, S., Boyd-Harlow, D., \& McKean, M. (2012). Developing the learning physical science curriculum: Adapting a small enrollment, laboratory and discussion based physical science course for large enrollments. Physical Review Special Topics-Physics Education Research, 8 (1), 010121.

[14] Abd-El-Khalick, F. (2001). Embedding Nature of Science Instruction in Preservice Elementary Science Courses: Abandoning Scientism, But... Journal of Science Teacher Education, 12 (3), 215-233.

[15] Otero, V. K. \& Gray K. E, (2008). Attitudinal gains across multiple universities using the Physics and Everyday Thinking curriculum. Physical Review Special Topics-Physics Education Research, 4 (2), p. 020104. 
[16] Lindsey, B. A., Hsu, L., Sadaghiani, H., Taylor, J. W., \& Cummings, K. (2012). Positive attitudinal shifts with the Physics by Inquiry curriculum across multiple implementations. Physical Review Special Topics-Physics Education Research, 8 (1), 010102.

[17] Palmer, D. H. (2002). Factors contributing to attitude exchange amongst preservice elementary teachers. Science Education, 86 (1), 122-138.

[18] Haynes, P., Ip, K., Saintas, P., Stanier, S., Palmer, H., Thomas, N., \& Maillardet, F. (2004). Responding to Technological Change IT Skills and the Academic Teaching Profession. Active Learning in Higher Education, 5 (2), 152-165.

[19] Harlen, W., \& Holroyd, C. (1997). Primary teachers' understanding of concepts of science: Impact on confidence and teaching. International journal of science education, 19 (1), 93-105.

[20] Jarrett, O. S. (1999). Science interest and confidence among preservice elementary teachers. Journal of Elementary Science Education, 11 (1), 49-59.

[21] Mulholland, J., \& Wallace, J. (1996). Breaking the cycle: Preparing elementary teachers to teach science. Journal of Elementary Science Education, 8 (1), 17-38.

[22] Tosun, T. (2000). The beliefs of preservice elementary teachers toward science and science teaching. School science and mathematics, 100 (7), 374-379.

[23] Yates, M. S., \& Goodrum, D. (1990). How confident are primary school teachers in teaching science? Research in Science Education, 20 (1), 300-305.

[24] Rennie, L. J., Goodrum, D., \& Hackling, M. (2001). Science teaching and learning in Australian schools: Results of a national study. Research in Science Education, 31 (4), 455498.

[25] Appleton, K., \& Kindt, I. (1999). How Do Beginning
Elementary Teachers Cope with Science: Development of Pedagogical Content Knowledge in Science.

[26] Jarvis, T., \& Pell, A. (2004). Primary teachers' changing attitudes and cognition during a two-year science in-service programme and their effect on pupils. International journal of science education, 26 (14), 1787-1811.

[27] Gunning, A. M., \& Mensah, F. M. (2011). Preservice elementary teachers' development of self-efficacy and confidence to teach science: A case study. Journal of Science Teacher Education, 22 (2), 171-185.

[28] Rice, D. C., \& Roychoudhury, A. (2003). Preparing more confident preservice elementary science teachers: One elementary science methods teacher's self-study. Journal of Science Teacher Education, 14 (2), 97-126.

[29] Lewis, L. (1999). Teacher quality a report on the preparation and qualifications of public school teachers. DIANE Publishing.

[30] Nanes R., Inquiry Into Physical Science: A Contextual Approach (Kendall-Hunt, Dubuque, IA, 2008), Vols. 1-3, 2nd ed.

[31] Loverude, M. E., Gonzalez, B. L., \& Nanes, R. (2011). Inquiry-based course in physics and chemistry for preservice K-8 teachers. Physical Review Special Topics-Physics Education Research, 7 (1), 010106.

[32] Strawitz, B. M., \& Malone, M. R. (1986). The influence of field experiences on stages of concern and attitudes of preservice teachers toward science and science teaching. Journal of Research in Science Teaching, 23 (4), 311-320.

[33] Adams, W. K., Perkins, K. K., Podolefsky, N. S., Dubson, M., Finkelstein, N. D., \& Wieman, C. E. (2006). New instrument for measuring student beliefs about physics and learning physics: The Colorado Learning Attitudes about Science Survey. Physical Review Special Topics-Physics Education Research, 2 (1), 010101. 